Revista Iberoamericana, Vol. LXXXV, Núm. 267, Abril-Junio 2019, 477-496

\title{
“DECLARACIONES DE MODERNIDAD” EN LA REVISTA PERUANA VARIEDADES (1908-1932)
}

\author{
POR \\ María Chiara D'Argenio \\ University College London
}

En la década de 1920 aparecen en el Perú una serie de reflexiones teóricas sobre lo que se entiende por "sensibilidad" y "vida" modernas, relacionadas ambas con la tecnología, percepción, experiencia y subjetividad. Se trata de textos producidos por un grupo selecto de intelectuales y publicados en las páginas de varias revistas. En 1924, en Variedades, en su artículo "Post-impresionismo y cubismo", José Carlos Mariátegui afirma que "La vida actual tiene elementos físicos absolutamente nuevos. Uno de ellos es la velocidad. El hombre antiguo marchaba lentamente, [...] El hombre contemporáneo viaja en automóvil y en aeroplano" (Variedades 827). En 1926, desde las páginas de Favorables París Poema, César Vallejo declara la existencia de una subjetividad moderna, que se caracteriza por una nueva sensibilidad, derivada del impacto producido por las nuevas tecnologías y por una particular "emoción cinemática". En 1927, María Wiesse, desde Amauta, en un texto que titula "Señales de nuestro tiempo", explica lo que entiende por vida moderna utilizando términos parecidos a aquellos empleados por Mariátegui y Vallejo:

El ritmo precipitado [...] de la vida moderna concuerda perfectamente con el ritmo intenso y nervioso del cinema. Esta época es la época de la imagen, que triunfa sobre la palabra. [...] No hay que alarmarse por este gusto exagerado por la imagen. Es una señal de la sicología de nuestro tiempo y revela la relación que existe entre estos dos dinamismos: el del espíritu moderno y el de las moving pictures. (11-12)

\footnotetext{
1 Este ensayo está basado en una investigación llevada a cabo en la Colección Pedro Benvenutto en la Biblioteca de la Universidad del Pacífico de Lima entre 2010 y 2015. Quiero expresar mi agradecimiento al profesor Jorge Wiesse, a la directora de la biblioteca Lic. Rosa Dorival y a Milagros Ríos por su asistencia y apoyo durante mi investigación. Agradezco también a Fanni Muñoz Cabrejo por haberme brindado una copia de su libro. Las imágenes incluidas en este artículo fueron tomadas por la autora de los ejemplares de las revistas que se encuentran en la Colección Benvenutto. Las traducciones al español son mías. Parte de las ideas presentadas en este artículo han sido desarrolladas y discutidas en detalle de un capítulo (2016) y dos artículos (2017 y 2019), incluidos en la bibliografía.
} 
Mariátegui parece enfocarse en la nueva tecnología, pero puede argüirse que lo que subraya es la nueva experiencia. Sus comentarios señalan una nueva sensibilidad creada por los tiempos modernos al afirmar que se hace necesario ser "espiritualmente modernos". Vallejo y Wiesse van más allá. Su aproximación explora la psique y la subjetividad al vincular la vida moderna a procesos mentales y emotivos. Para Vallejo son "nuevos temples nerviosos" y "profundas perspicacias sentimentales" en una "psicología de nuestro tiempo" en donde prima lo visual y lo dinámico, mientras que Wiesse establece una relación analógica entre vida moderna y una tecnología visual particular, el cine, al hacer corresponder el nuevo dinamismo ("intenso y nervioso") con los atributos que parecen pertenecer a la edición cinematográfica ("precipitado" e "inarmónico"). Un año después de los textos de Vallejo y Wiesse, otro intelectual, Clodoaldo Espinoza, también desde Variedades, se enfoca en la relación entre cine y modernidad proponiendo un paralelismo todavía más explícito: "La síntesis, velocidad y objetivismo del cine corresponden a características de nuestra época: concisión, rapidez y claridad"; y planteando el cine como una "guía" para entender la actualidad moderna: "Para latir según el ritmo de la época", declara Espinoza, "hay que estudiar de cerca el fenómeno cinematográfico" (Variedades n. 1018, 1927).

El tipo de "vida moderna" de principios del siglo XX presentada por estos intelectuales está caracterizada por el dinamismo de las nuevas tecnologías, algo que se vincula claramente con los discursos del progreso. Pero ellos subrayan también una nueva sensibilidad o subjetividad vinculadas a la percepción, en particular la visualidad. Tal énfasis permite pensar la modernidad como experiencia traída por los cambios epistemológicos, físicos, culturales y políticos de la modernización, en el sentido que le da Marshall Berman (1-2). El tipo de circulación contemporánea de estas ideas autorreflexivas, por otro lado, nos ofrece claves para entender, en general, el rol de las revistas en la sociedad peruana (y latinoamericana) de esa época y, en particular, en su modernización.

A diferencia de las revistas en que publican Vallejo y Wiesse, reconocidas como especializadas y de vanguardia, Mariátegui y Espinoza publican en una revista popular ilustrada, Variedades (1908-1932), que responde a un formato comercial, el del "magazine", implementado en Europa y las Américas entre finales del siglo XIX y principios del XX. Variedades fue fundada en Lima por el fotógrafo portugués Manuel del Moral y Vega (1865-1913), quien, después de haber creado la revista de élite Prisma (1905-1907), decidió lanzar un semanario que correspondiera al formato, al público y a la circulación que buscaban las nuevas tendencias internacionales en los medios masivos. El formato "magazine" de Variedades se inventa de manera simultánea en los Estados Unidos y en Europa y responde tanto a una serie de innovaciones tecnológicas (la prensa offset, el semitono) como a los criterios escogidos por los editores en ambos lados del Atlántico. Variedades se planteó desde un principio como una revista dirigida a un público amplio y como una publicación que haría de

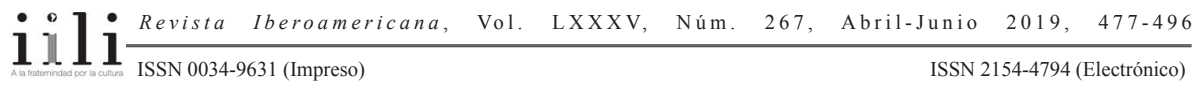


la tecnología visual uno de sus ejes. Tenía tamaño reducido y una gran variedad de contenido y de formas gráficas. En sus páginas se trataba política local y extranjera, eventos sociales, descubrimientos científicos, amenidades y últimas noticias del Perú y del mundo; y todo esto se mostraba mediante dibujo, grabado, litografía, fotografía, y formas viso-textuales como la caricatura y la historieta. En línea con publicaciones contemporáneas europeas y norteamericanas, las decisiones editoriales respondían al imperativo de lo "corriente" y al vocabulario de lo nuevo. A diferencia del tipo de revista que las predecía, los magazines conformaban una esfera de debate público a través ya no de "juicios [...] y prestigios" (Ossandon y Santa Cruz 10), sino de publicidad, sport, modas, diversiones, actualidades, vida social; su lógica era la de "integración" (Rogers 209) y su contenido era híbrido: el editorial político coexistía con la noticia de moda y el reportaje de eventos sociales; su finalidad era entretener y persuadir, y no tanto instruir, a un público entendido más y más como consumidor. Los objetivos de Variedades fueron claramente articulados en el primer número:

En los países latinos, y en especial en América, las revistas sólo se hacen populares cuando en ellas se da principal cabida á [sic] la nota regocijada, humorística, espiritualmente satírica. El editor y director de Prisma, comprendiéndolo así, han resuelto trasformar esa revista de una manera que la haga más popular, más amena, más casera, más interesante. (Variedades, número Prospecto, febrero de 1908)

Revistas como Variedades se proponen no solo aligerar el contenido (haciéndolo brevey ameno) de sus predecesoras, sino también hacerse accesibles a un público diverso y numeroso, y, sobre todo, llegar al espacio de la vida cotidiana, de la privacidad de las familias y los individuos; es decir, establecer un vínculo con su experiencia presente y futura, especialmente la citadina. Su formato daba centralidad tanto a los textos breves como a las imágenes, al material misceláneo y, sobre todo, a la publicidad. En concreto, constituían signos materiales de modernización, eran tanto productos del capitalismo y participantes en una incipiente industria cultural como artefactos culturales que familiarizaban la modernidad a través de sus contenidos. Esas revistas, como explica Geraldine Rogers a propósito de Caras y Caretas, eran "destinad[as] a un uso fragmentario, rápido y extensivo que reproducía la mezcla desprejuiciada que era parte de la experiencia vivida por sus lectores en el collage urbano" (38). La fragmentariedad y rapidez de experiencia urbana, a la que se refiere Rogers, se correspondía con una actividad de lectura y/o hojeo que reproducía el ritmo "dinámico" y "disarmónico" del nuevo tipo de vida. Al ser publicadas en Variedades, las reflexiones teóricas de Mariátegui y Espinoza sobre vida moderna se convierten tanto en unas entre las muchas maneras en que la revista representa la modernidad como experiencia y la transforma en sentido común, como en una manera en que la revista "construye" una noción de vida moderna para la comunidad imaginada de ciudadanos peruanos.

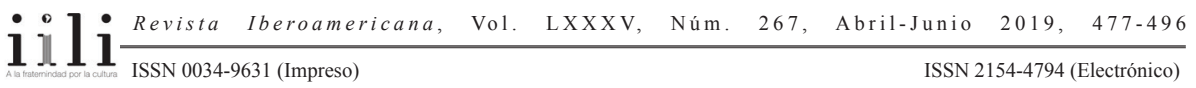


La relación entre Variedades y la modernidad peruana, entendiendo la modernidad tanto como una experiencia determinada por los cambios que se identifican con el término de modernización, como una formación discursiva que se elabora en momentos históricos específicos en respuesta a dichos cambios, es el campo de exploración del presente artículo. Mi discusión se enfoca en tres ejes: la tecnología, en particular del cine, usada para articular una noción de modernidad como progreso, contemporaneidad y cosmopolitismo; la manera en que la revista construye lo que llamo una "ciudadanía imaginada"; y el espacio de la revista como lugar de enunciación de lo que William Rowe ha llamado "declaraciones de modernidad" (21). El análisis de estos tres aspectos me permitirá concluir que, en el contexto de la modernización y los discursos sobre el progreso de las primeras décadas del siglo XX, Variedades se presenta como un espacio discursivo que contiene nociones y declaraciones conflictivas con respecto a la idea de modernidad como progreso lineal, y que plantea, más bien, a través del caso peruano, la existencia concreta de la modernidad como una experiencia no de progreso secuencial y lineal, sino de negociaciones y conflictos que parecen ser parte intrínseca de un cambio que no ha de tener fin.

\section{CINE, PROGRESO, CONTEMPORANEIDAD Y COSMOPOLITISMO}

La tecnología cinematográfica, y el cine como evento público, forman parte de esta experiencia de permanente negociación y conflicto. La relación entre cine y modernidad ha sido explicada por Leo Charney y Vanessa Schwartz (3) como una de "reflejo y convergencia": el cine compartía con la vida moderna elementos tales como el desarrollo de un público masivo, la dialéctica entre lo efímero y lo estático, la confusión de los límites entre la realidad y su representación y el surgimiento tanto de una cultura comercial como de un deseo hacia el consumo. Si bien los intelectuales propusieron una teorización coherente en los años veinte, las primeras reflexiones sobre el cine habían empezado antes, en el Perú como en el resto de Latinoamérica, con las primeras crónicas y artículos periodísticos modernos. La proyección de imágenes en movimiento empezó en Lima tan solo un año después de la exhibición del cinematógrafo en París, y tuvo lugar el 2 de enero de 1897 en el Jardín Estrasburgo, un restaurante del centro de Lima. ${ }^{2}$ Se trató de una función del vitascopio de Edison organizada para un público selecto. En el mismo local se presentó, un mes más tarde, el 5 de febrero, el cinematógrafo Lumière. Las primeras crónicas periodísticas peruanas sobre el cinematógrafo destacaron la "magia" del movimiento, el "realismo" y la "ilusión de realidad" otorgados por la nueva tecnología. Más aún, además de resaltar el movimiento, la vitalidad en los cuerpos y la fidelidad para con la realidad representada,

2 Para la historia del cine silente peruano, ver Bedoya 2009 y Nuñez Gorriti 2010.

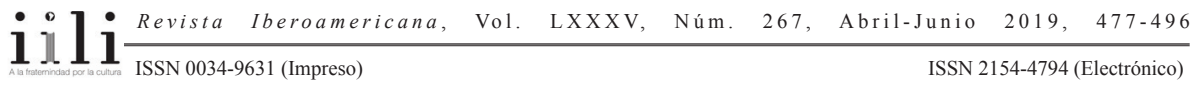


una crónica detallada de la primera exhibición del vitascopio Edison, publicada el 4 de enero de 1897 en el periódico El Comercio, menciona un aspecto que fue central en los discursos sobre el cine y en la manera en la que las imágenes en movimiento afectaron la percepción espaciotemporal, es decir, la simultaneidad:

¡Qué maravilla oír en Lima la voz de un cantante que nunca ha pisado esta ciudad y que en la fecha se hallará, quién sabe si en Nueva York, o en Londres, o en la Eternidad! [...] tanta fidelidad y exactitud hay en este cuadro que verdaderamente sorprende y cautiva al espectador [...] Causando la ilusión más grata y embelesando a los espectadores, [...]. (Bedoya, El Comercio, 4 ene. 1897) ${ }^{3}$

El cronista resalta la realidad de encontrarse ante la presencia de una persona en dos lugares distintos, y con ello, considerando la actualidad implícita de su espectáculo, la presencia de la modernidad en dos lugares distintos. Más aún, y por translación, se resalta la presencia del público de Lima en el espacio cosmopolita de Nueva York o Londres y lado a lado con los citadinos internacionales. Temporalmente, se va aún más lejos, no solo el tiempo de Lima se sincroniza con el tiempo inmediatamente anterior, ya moderno, de las grandes ciudades cosmopolitas, sino que también se hace partícipe de la anulación tecnológica de las limitaciones del tiempo humano al hacer revivir a una artista que hipotéticamente pudo haber ya fallecido.

Diferenciándose de las crónicas de los periódicos sobre el cine como evento espaciotemporal de élites, la revista otorga un significado geopolítico a la noción de simultaneidad y pone en acción lo que Wolfgang Bongers define como la "estrategia de hacer del cine un agente popular de progreso cultural, científico y artístico"(155). En 1908, por ejemplo, una nota dedicada a comentar el próximo estreno del nuevo cinematógrafo Gaumont en el recién construido teatro Olimpo señala que el reconocido empresario a cargo del evento había ya organizado el envío de "50 películas quincenales con las últimas novedades y acontecimientos europeos". Los términos "último", "novedad", "actualidad" recurren contribuyendo a construir la percepción de contemporaneidad y la sensación de sincronía para con el mundo europeo. La nota se cierra afirmando que "El público del Olimpo tendrá, pues, siempre sin más diferencia que el término de la distancia, las vistas que en París y en Europa constituyen la novedad cinematográfica" (Variedades n. 37, 1908 "En el cine Gaumont”). La cubierta del número 317 de 1914 (fig. 1), por otro lado, lleva una caricatura que muestra las películas como vehículos que traen al Perú las últimas novedades tecnológicas de todo el mundo disminuyendo las distancias entre Lima y los otros países "civilizados".

Debido a que las imágenes a las que los espectadores latinoamericanos tenían acceso eran, en su mayoría, vistas de "otras" ciudades modernas - preponderantemente

3 La crónica es recopilada tanto en Bedoya 2009 como en Nuñez Gorriti 2010.

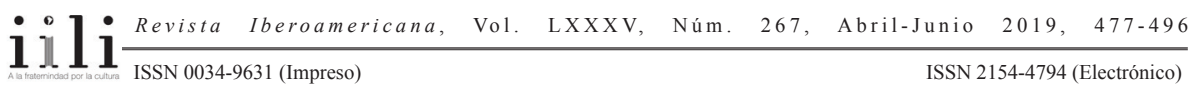




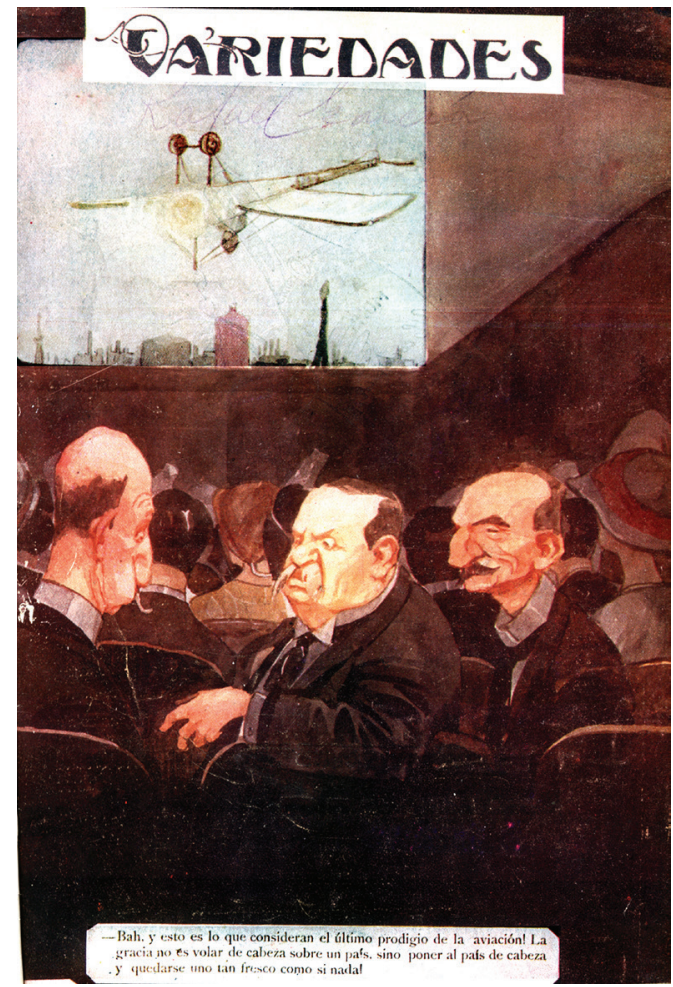

Fig. 1: Variedades n. 317, 1914

europeas en las primeras décadas-el cine temprano en América Latina se caracterizó por lo que Ana López define como una dialéctica del acto de "ver". López arguye que la experiencia latinoamericana del cine temprano constituyó un voyerismo hacia (más que una participación en) el progreso y la modernidad producidos en otros lados (152-53). El texto de Variedades, sin embargo, permite ir más allá de la noción de modernidad importada y pensar el cine-evento como experiencia, y la experiencia de modernidad ofrecida por la tecnología e imágenes cinematográficas como una de cosmopolitismoycontemporaneidad. En este sentido, el cine constituyó uno más de una serie de "signos" de contemporaneidad y cosmopolitismo presentes en larevista. Otros erantanto las secciones: "Modas europeas", "Caricatura en el extranjero" y "Frivolidades parisienses", como las noticias de actualidad extranjera y las notas de difusión sobre descubrimientos científicos y tecnológicos ocurridos en varias partes del mundo. Todos ellos eran referentes que brindaban a los lectores de Variedades la sensación de formar parte de una globalidad.

El cosmopolitismo contemporáneo que la revista promovía debe entenderse en un sentido también político puesto que, como señala Fanni Muñoz Cabrejo en su libro Diversiones públicas en Lima (1890-1920), el cosmopolitismo en el Perú de principios de siglo era un ideal clave de las políticas reformadoras que empezaron con el segundo gobierno de Nicolás de Piérola (1895-1899) después de la fase de la llamada Reconstrucción Nacional que siguió a la derrota de la Guerra del Pacífico (1879-1884). A partir del gobierno de Piérola, se produjeron las condiciones que permitieron cierta estabilidad política. Esto favoreció un proceso de cambio dirigido a la modernización del estado. Esta inicial modernización continuó durante las primeras tres décadas del nuevo siglo apoyada por las políticas de los llamados República Aristocrática (18951919) y Oncenio de Leguía (1919-1930). A pesar de las diferencias entre esas etapas 
políticas, las nociones de progreso y cosmopolitismo fueron los ideales de una ideología dominante de matriz positivista que venía del siglo anterior.

Lo que identifico como modernidad dominante se corresponde con lo que Nicola Miller ha llamado modernización tecnocrática; es decir, como ella lo explica: "la promoción de una ideología del progreso definida primariamente en términos de economía, sostenida por la razón instrumental y la tecnología, e implementada por una elite del saber" (14). La noción de modernidad como progreso, contemporaneidad y cosmopolitismo, respaldada, defendida y difundida por el proyecto de Variedades puede entenderse políticamente como articulación de un discurso hegemónico o, tomando la terminología de Rowe, como una declaración de modernidad dominante. A pesar del tratamiento alegórico en imágenes de linealidad causal, continua y tecnológica que la revista lleva a cabo, tales como la cubierta de su número 976, de noviembre de 1926, que lleva por título "La carrera de mañana" y muestra el automóvil del "progreso nacional" liderando una competencia por el desarrollo (fig. 2), como Rowe arguye, la modernidad peruana no debe entenderse como una experiencia lineal y progresiva sino como una serie de momentos y declaraciones. La articulación de texto, imagen y mecánica general de la revista constituirían un evento discursivo de declaración de modernidad hegemónica. La historia del Perú, de acuerdo a Rowe, se ha caracterizado por la presencia simultánea de declaraciones y "contradeclaraciones" de modernidad. Como la cubierta de la fig. 2 revela, una de las declaraciones de modernidad que se encuentran en la revista es precisamente la noción de tipo positivista; sin embargo, como mostraré más adelante, Variedades articula asimismo otro tipo de declaraciones de modernidad.

Ciudadanía imaginada

El estado peruano asumió el rol de "moderador, promotor e integrador" (Contreras y Cueto 211-12) del

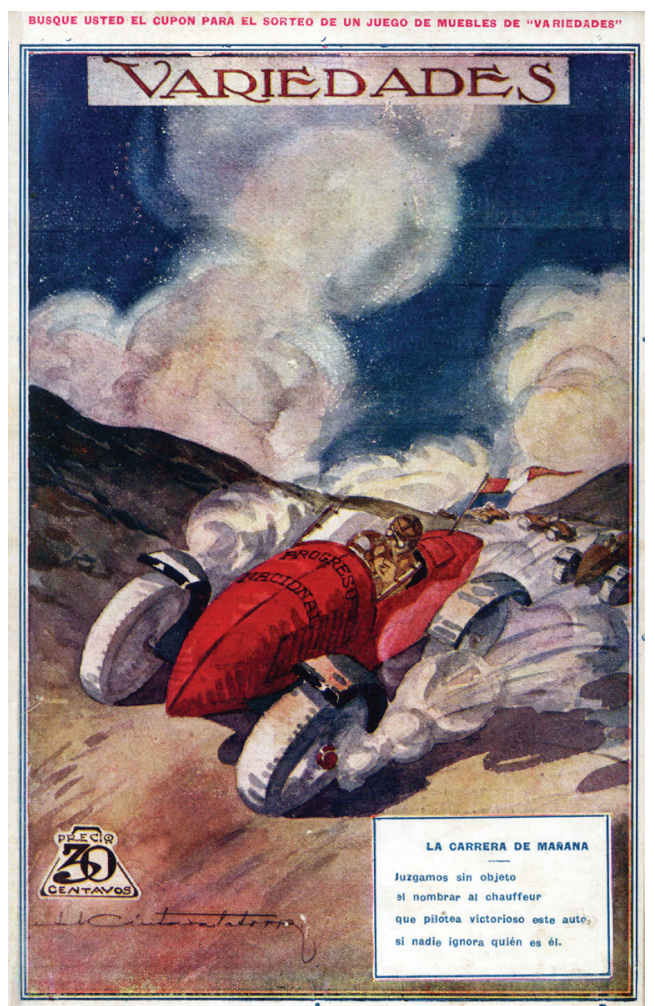

Fig. 2: Variedades n. 976, 1926

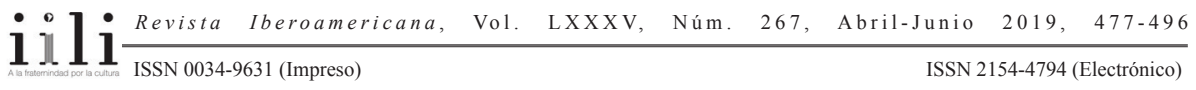


proceso de modernización. Como tal, debía educar a los habitantes del país (a través de las leyes en materia de trabajo, educación, salud y diversiones, de campañas sanitarias, de operaciones culturales, así como de la reorganización del espacio público) y hacer de ellos ciudadanos a partir de un tipo ideal. Entre los atributos que debían poseer quienes se entendían como ciudadanos modernos se encontraban el cosmopolitismo, el progreso, la productividad, la moralidad y la salud (Muñoz Cabrejo 58). Dentro de este contexto, una revista como Variedades participa en la formación de lo que podría llamarse, arguyo, adaptando la conocida noción de Benedict Anderson acerca de la nacionalidad(1983), una “ciudadanía imaginada". Por “ciudadanía imaginada", entiendo el proyecto representado en imágenes (visuales y metafóricas) de los ciudadanos, de sus valores y comportamientos. ${ }^{4}$ En las imágenes, el progreso, la contemporaneidad y el cosmopolitismo se vuelven entonces no solo ideales de una ideología dominante sino también atributos de los ciudadanos ideales que el capitalismo impreso trata de construir.

Variedades apoyó la noción dominante de ciudadanía a través de imágenes que promovían una figura en buen estado físico. Grabados y fotograbados eran parte de artículos y secciones específicas dedicadas a la salud, el deporte y las modas europeas con un enfoque especial en la publicidad relacionadas con el cuerpo. Deportes como el fútbol, el boxeo, el turf tenían particular cobertura en sus páginas. Otras imágenes, como las fotografías de las obras públicas, presentaban el resultado del trabajo de aquellos cuerpos útiles. En términos de las actividades generales y conducta de los ciudadanos, como he argüido en otro trabajo, las estrategias empleadas por la revista para construir una noción de ciudadanía imaginada fueron la categoría de lo "cotidiano" y una "mirada costumbrista". Siendo una revista que se publicaba semanalmente y que resumía, ilustraba y comentaba los eventos ocurridos durante la semana centrándose en particular en las novedades y las actualidades de la vida limeña, Variedades estaba organizada alrededor de la categoría de lo cotidiano. A lo cotidiano pertenecía también el espacio dedicado, comercial e informativamente, a lo doméstico. Y en el espacio de lo cotidiano público y privado es donde se lleva a cabo lo que denomino "mirada costumbrista". Me refiero aquí a "una práctica de la mirada que interpreta la sociedad representando las costumbres y comportamientos cotidianos de la gente; que ofrece el retrato de una sociedad dividida en grupos sociales separados mientras brinda simultáneamente imágenes de coexistencia y porosidad con el fin de persuadir a sus lectores-espectadores a que consuman visiones de movilidad social" (D'Argenio "From Spectators to Consumers" 25). El costumbrismo fue una tradición visual (pictórica) y escrita (periodística) basada en la observación. Consistió en la realización de

Para una discusión más extensa de la noción de ciudadanía imaginada en las revistas peruanas, ver mi artículo "From Spectators to Consumers".

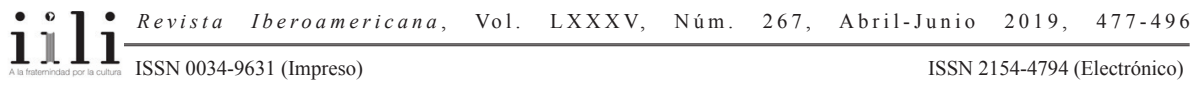


descripciones de ambientes, prácticas y costumbres sociales a ser corregidas a través de, en lo pictórico, las llamadas "escenas de costumbres", y, en lo literario, "cuadros de costumbres", un tipo de crónicas periodísticas que empleaban la sátira para discutir cuestiones políticas y sociales actuales. El costumbrismo, tanto en su variante visual como textual, estaba enfocado en la actualidad y en lo efímero, en la identificación de grupos y categorías sociales de la nación y en su proceso de transición. Como lo era el costumbrismo histórico, se trataba también de la producción de imágenes que fueran consumibles por un público vasto. Variedades construye modelos de ciudadanos valiéndose de esta mirada costumbrista enfocada en la actualidad, en lo cotidiano y en una sociedad dividida y hasta tipificada.

La mirada costumbrista de Variedades no articula con claridad una noción de ciudadanía imaginada que sigue la ideología dominante representando una dirección progresiva a seguir que debe dejar detrás suyo ciertas actitudes y comportamientos. La ciudadanía que articula la revista es más bien multidireccionalmente dinámica, compleja y ambivalente. Esto se advierte con claridad en la publicación en sus páginas, en 1922, del texto costumbrista "El té y la mazamorra", escrito originalmente en 1841 por Manuel Ascensio Segura. Se trata de un retrato satírico tanto de la política peruana de los años inmediatos a la independencia como de una sociedad que se encuentra negociando en pleno el espacio de las viejas tradiciones locales y la presión de los nuevos modelos culturales foráneos. La pugna entre localismo y cosmopolitismo se representa alegóricamente a través de un motivo culinario que identifica lo moderno con los hábitos extranjeros: "La moda del té con leche", escribe Segura, "ha remplazado el chocolate que tomaban nuestros abuelos y ahora toman solo aquellos que se parecen a los que no entran por las reformas y por el buen gusto moderno" (Variedades n. 742 , 1922). La sociedad limeña que Segura describe está dividida en tres sectores: aquellos que, como los ingleses, beben té y tienen un "refinado gusto moderno", como ocurre tanto con el anónimo protagonista principal -un "reformador / reformista / reformado"-, como con su amigo Don Antonio y con los europeos con quienes discute de política contemporánea; aquellos que beben chocolate caliente, como los viejos sectores antiliberales; y los sectores que tienen un gusto más popular, como el de Doña Rosita, la esposa de don Antonio, quien es una limeña contemporánea que, a pesar de haber esposado un hombre de avanzada, no adopta los nuevos comportamientos sino que prefiere la mazamorra criolla: "Hermosa limeñita, Doña Rosita [...] casada con un moderno, no ha podido convenirse jamás con las costumbres modernas; y por consiguiente no es de las que toman té, ni cosa que se le parezca, porque dice que una taza de mazamorra morada es mejor que veinte de té con leche" (Variedades n. $742,1922)$. Al publicar este articulo costumbrista ocho décadas más tarde, Variedades deja en claro que esta negociación es un proceso que todavía continúa casi un siglo después; $y$, al incluir en sus páginas anuncios que publicitan el chocolate caliente y

\begin{tabular}{l}
1110 \\
\hline ISSN 0034-9631 (Impreso)
\end{tabular} 
al dar espacio a otras prácticas "criollas" populares que contrastaban con lo europeo moderno, la revista, como señalé anteriormente, se hace un espacio de inclusión de modelos de comportamientos opuestos al proyecto oficial progresivo.

Ejemplos visuales de este fenómeno no solo se encuentran en la conducta local representada en las imágenes satíricas, sino también en imágenes que representan maneras en las cuales el voyerismo del acto de "ver" de los locales constituye una actitud moderna y, por naturaleza, conflictiva. Y esto es lo que sucede en las representaciones relacionadas al espectáculo cinematográfico, imágenes que representan no solo las imágenes en movimiento en la

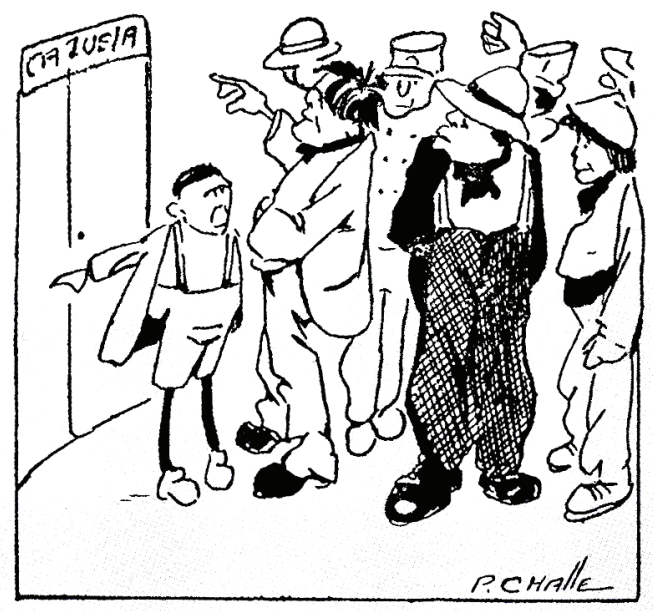

-Caray! La verdad que es cara la cazuela, pero vale la pena para rolarse con la gente decente.

Fig. 3: Variedades n. 49, 1909 pantalla, sino también la dinámica moderna de su experiencia. La figura 3 es una viñeta de humor gráfico que, por ejemplo, muestra el cine de manera muy distinta a como se llevó a cabo a fines de siglo en el Jardín Estrasburgo; la experiencia directa de este evento ya en el siglo veinte es una manera de "mezclarse" con la gente "decente"; es decir, participar de la modernidad no es convertirse en el espectador ideal y ser un ciudadano poseedor de los atributos planteados por la ideología dominante, sinonegociar una contigüidad permitida por un espacio en el que la mezcla social jugando el papel de voyeur es la modernidad. El segundo ejemplo me lleva otra vez al cine.

He argüido que el cine fue discursivizado como agente de progreso y también como manera de imaginar o realizar una movilidad social; ahora quiero mostrar además que Variedades presenta el cine como elemento de una modernidad que es causa de degeneración moral. Por un lado, los artículos celebran que por fin se hubiese construido teatros que eran dignos espacios de la cultura del cinematógrafo; por otro lado, en una caricatura de 1912 (fig. 4), el cine se representa como un lugar que alberga y hasta promueve los vicios y la conducta inaceptable. Esta última imagen muestra que una nueva inmoralidad estaba directamente asociada a los cambios traídos por esa tecnología moderna. Las relaciones sociales y de pareja cambiaron radicalmente con

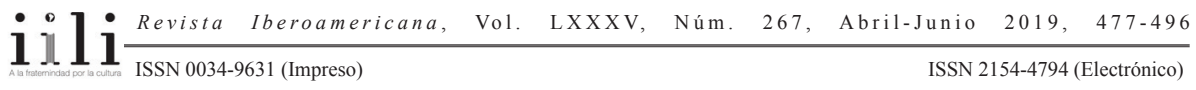




\section{Espectáculos}

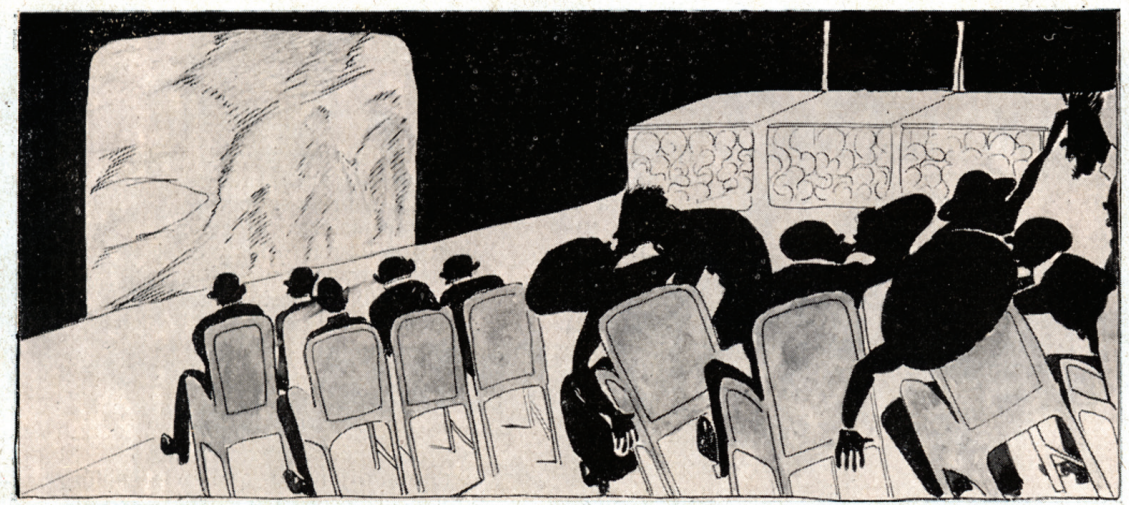

El Cine: para los chicos y para los grandes

Fig. 4: Variedades n. 210, 1912

la implementación de los cines: "Una vez que apareció el cinematógrafo en Lima", escribe el poeta José Gálvez en 1913:

el amor o el enamoramiento [...] sufrió una decisiva transformación. [...] El cinema traía local propicio, ocasiones múltiples, penumbra, rumor, y lecciones objetivas de toda clase, para toda condición o estado. Una vez que se implantó la tanda 'vermouth', o sea la tanda de la libertad, a la que se puede ir sin acompañante serio, los enamorados comenzaron a citarse en los locales. ${ }^{5}$

Dicha mezcla, contigüidad y ambivalencia moral no se resolvió ni con el pasar de los años ni con la continuidad del progreso tecnológico; y no fue únicamente representada en Variedades. La figura 5 es una viñeta publicada en el número 67 de la revista ilustrada Mundial, en 1921. La imagen identifica las raíces de la "inmoralidad" del cine no en las imágenes en movimiento sino en la experiencia cinematográfica que hacía necesaria la cercanía de los cuerpos. En el mismo año, también en Mundial, un artículo firmado por el colaborador europeo P. Chaumet afirma que del cine "resta únicamente saber si su imperio sobre el espíritu de las multitudes es bueno o es nocivo; si las consecuencias de esta atracción formidable que él ejerce particularmente entre la juventud, no constituyen un factor principal de cierta degeneración intelectual" (Mundial n. 52, 1921). Para 1925, en Variedades, Héctor Velarde toma distancia definitiva del

\footnotetext{
La cita se encuentra en Bedoya (2009) 81.
}

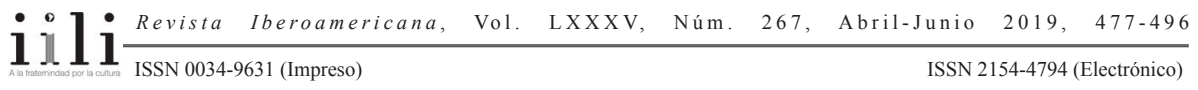




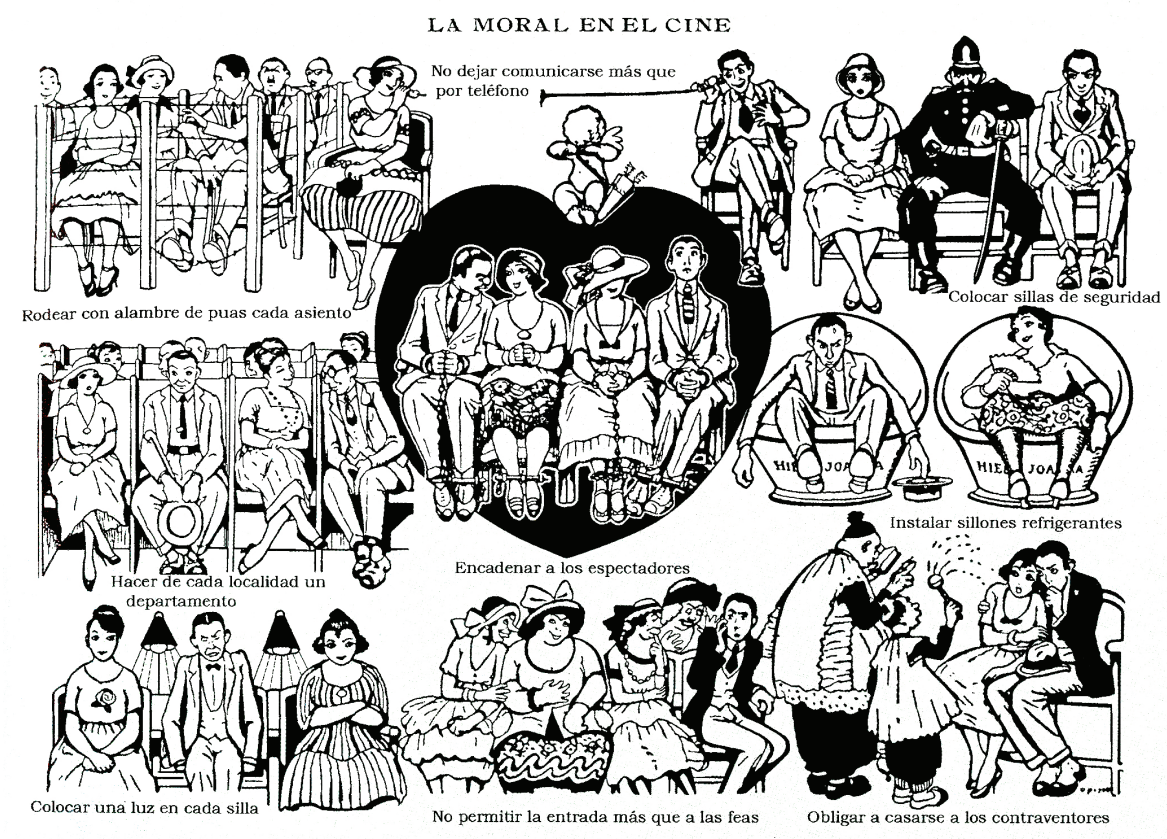

Fig. 5: Mundial n. 67, 1921

tipo de evento que originalmente ofreció la primera proyección cinematográfica en Lima. El cine es para él un "espectáculo imperfecto que adormece el espíritu y acaricia los sentidos. De allí su éxito universal y alarmante. [...] El artificio [del cine] engaña a los sentidos gustosos de mentira [...] El cine degenera en vicio. Ahí está el porqué de su triunfo" (Variedades n. 897, 1925). Paradójicamente, el cuerpo sano, educado y productivo del discurso dominante de la modernidad se encuentra contiguo y mezclado con el cuerpo indulgente y excesivo de la modernidad. El cosmopolitismo cultural elogiado por muchos periodistas e intelectuales es visto por otros, más conservadores, como un peligro social; el problema es que, tal como lo presenta la revista, ambas facetas parecen ser parte del mismo fenómeno. Los conservadores identificaban la inmoralidad con los modelos foráneos de comportamiento que los gobiernos proponían como ideales y las películas difundían. Si, por un lado, se propuso la posibilidad de usar el cinematógrafo como instrumento educativo en las escuelas, por el otro las películas son acusadas de enseñar inmoralidad.

Esta ambivalencia con respecto al cine es aun más relevante si tenemos en cuenta que la moralidad y las diversiones fueron dos elementos centrales de los debates y las reformas modernizadoras de principios del siglo. Como explica Muñoz Cabrejo, el

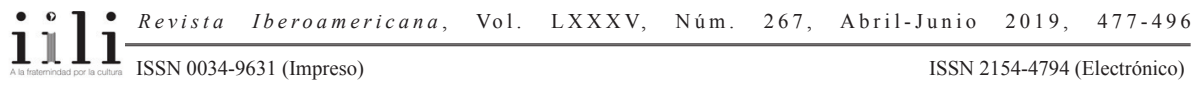


progreso del país consistía en llevar a cabo un "engrandecimiento moral” (61). Con el fin de fabricar nuevos ciudadanos, la élite modernizadora llevó adelante una campaña educativa en contra de lo que definió como la "inmoralidad de costumbres" de la sociedad limeña y sus prácticas tradicionales (Muñoz Cabrejo 58). Las características que poseía el individuo civilizado ideal: "amor al trabajo y a las leyes, mentalidad racional, nuevo comportamiento y gusto estético asociado a sensibilidad burguesa desde sentimiento de individualidad hasta refinamiento de comportamientos y costumbres" (57-58) eran opuestas a lo que se identificó como el estereotipo del limeño. Además de una reorganización del espacio urbano, de instrucción pública y de higienización, la campaña incluía un nuevo ordenamiento de las actividades recreativas con el fin de construir una ciudad y cultura urbanas que emularan las capitales europeas (37-50). Entre las diversiones públicas que fueron objeto de políticas restrictivas se encontraban prácticas tradicionales como las peleas de gallos y las corridas de toros, que eran consideradas irracionales, barbáricas e inmorales por los gobiernos de la República Aristocrática. En contraposición, se trató de promover actividades saludables y civilizadas como ciertos deportes y el teatro culto.

Como ocurría con eventos como el cine, la revista era también un artefacto, y hasta una tecnología, que hacía contiguos los opuestos y los diferentes e, inclusive, los mezclaba. Al contener las representaciones visuales y los discursos paradójicos del cine, Variedades actuaba además como un espacio no solo de reunión sino también de "integración”, una característica que Geraldine Rogers ha identificado en las revistas populares como género. En sus páginas Variedades también articula regular y hasta sistemáticamente el estado de las negociaciones entre lo antiguo y lo moderno; y muestra, por último, que la modernidad en el Perú no puede pensarse como una lineal "avenida del progreso", como muestra la portada "Nueva avenida" (fig. 6), en la que Augusto Leguía conduce una automóvil en una "recta avenida del progreso", sino como un proceso perenne de negociación. A pesar de sostener y colaborar en la construcción del discurso oficial del progreso, Variedades actuó como un mediador cultural y ofreció representaciones de diferentes tipologías de comportamiento y diversiones que a todas luces constituían la experiencia de la modernidad para sus lectores ciudadanos. Esta coexistencia ha sido estudiada desde el punto de vista de los estereotipos de género por Juan Miguel Espinoza (136), quien arguye que Variedades articuló una idea alternativa a la de modernidad que proponía el gobierno, una "modernidad criolla" que englobaba modelos sociales y culturales opuestos. Esto es evidente, afirma Espinoza, en su amplia cobertura periodística de prácticas "no civilizadas", tales como las corridas de toros, y en su defensa de modelos de género tanto modernos como tradicionales.

En esta defensa, el desarrollo del cine también jugó un papel clave. En 1924, meses antes de que Velarde lo acusara de ser un espectáculo que adormecía el espíritu y acariciaba los sentidos, alejando al espectador, se deduce, del ejercicio de su conciencia y

\begin{tabular}{l}
1110 \\
\hline ISSN 0034-9631 (Impreso)
\end{tabular} 


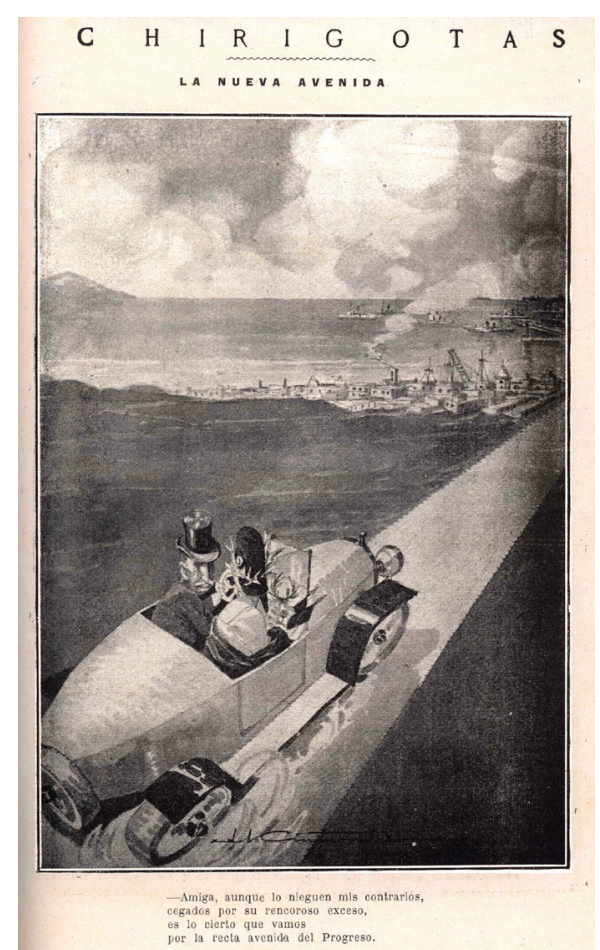

Fig. 6: Variedades n. 857, 1924 racionalidad, el número 852 de Variedades publicaba otro ejemplo de la coexistencia de modelos conflictivos en una entrevista exclusiva llevada a cabo por un reportero de planta, Juan Pesantes Ganoza, a una conocida actriz hollywoodiense. Reportero y entrevistada discuten temas relacionados con la modernidad en las esferas de lo público y lo privado: la moda, los estereotipos femeninos, la libertad y la moralidad. Ante la pregunta del periodista sobre el traje de baño que la actriz lleva en una de sus películas, ella responde reivindicando su derecho: “¿Por qué ocultar el cuerpo de una mujer? Yo creo que sería insultarle a un joven amigo mío si al momento de verlo corriera yo a cubrirme las piernas, eso sería decirle que su inmoralidad es tal que hay que evitarle la menor cosa que él pueda tomar mal" (Variedades n. 852, 1924). A diferencia de las películas que hacían posible pensar la modernidad como un tiempo y espacio simultáneos a partir de un acto de visión voyerística, esta entrevista permite la
ble por la alusión a su existencia. La actriz presencia directa del espectador hecha posible por la alusión a su existencia. La actriz llega a preguntarle a Pesantes Ganoza sobre la influencia de estos comportamientos "modernos" en la sociedad peruana y a inquirir si la gente en el Perú considera a las actrices norteamericanas un mal ejemplo. A manera de respuesta virtual, el periodista escribe unas líneas que se dirigen al público de Variedades: "Me quedé perplejo. ¿Qué contestarle a esta americanita cuando me hace esta pregunta con un traje de baño que no pesará más de una libra? ¿Qué contestarle, cuando en Lima hay señoras que para bañarse en una tina usan un traje de baño terriblemente largo?" (Variedades n. 852, 1924). Su comentario parece apoyar estereotipos femeninos conservadores, lo cual es confirmado por la leyenda escogida para la imagen "[la actriz] Luce un moderno e indiscreto traje de baño". Sin embargo, confirmando la ambivalencia discursiva (y visual) que caracteriza Variedades, la revista también publica imágenes titulares que desmienten esas visiones genéricas al mostrar modelos de mujer progresista (fig. 7). 
DeClARACIONES DE MODERNIDAD

En los mismos años en los que se discute la aparente dirección regresiva de la modernidad dominante, y Variedades articula una noción de modernidad de permanente contigüidad y conflicto entre 10 antiguo y lo moderno, lo local y lo foráneo, lo popular y lo elevado, y lo moral y lo inmoral, entre otras nuevas "mezclas", la revista publica, entre 1924 y 1925, una serie de artículos y fotografías sobre la región andina que, a pesar de no ser los primeros textos sobre esa zona, articularon por primera vez una narrativa contemporánea coherente sobre geografía, nación e identidad. Los textos fueron escritos en su mayoría por el intelectual cuzqueño y corresponsal de Variedades desde Cuzco, Carlos Ríos Pagaza; por

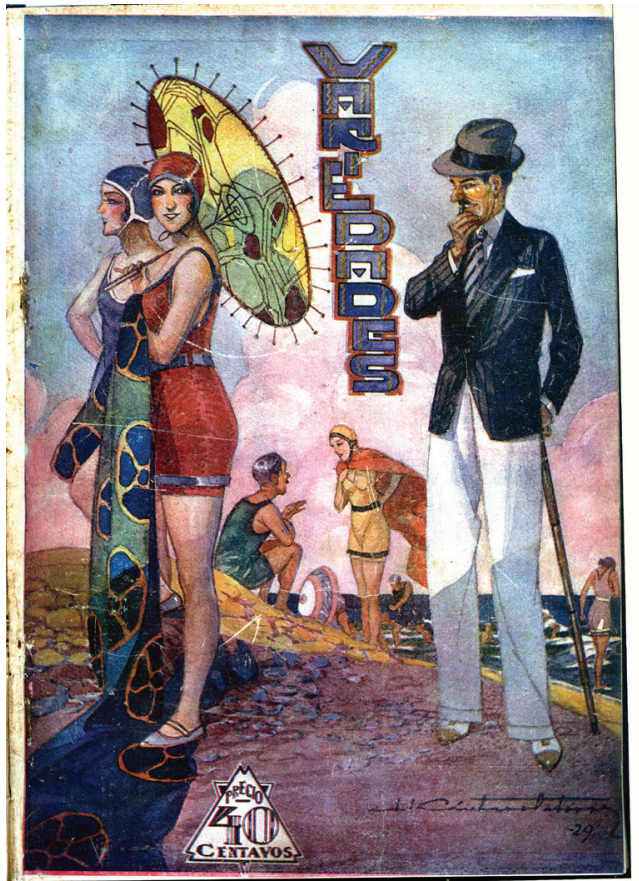

Fig. 7: Variedades n. 1100, 1929 lo menos uno fue escrito por el antropólogo Luis E. Valcárcel. Una de las particularidades de estos textos fue el lugar de su producción: una ciudad fuera de Lima que había sido la capital de la antigua nación. No solo los textos fueron escritos por cuzqueños, las imágenes eran enviadas por varios fotógrafos locales, entre ellos, el conocido Martín Chambi, uno de los corresponsales gráficos de Variedades. Estos reportajes dieron forma a un discurso declarativo progresista de modernidad que buscó colocarse contiguo al discurso del gobierno y competir con este en la esfera de lo oficial. Los reportajes contribuyeron a lo que Yasmín López Lenci (310-371) ha definido como la construcción de una "moderna cartografía del Cuzco", y mediaron las coevas propuestas indigenistas sobre la identidad y la nación peruana. Su discurso no se apoyaba en una noción de ciudadanía centrada en los cuerpos, su conducta y utilidad, sino en alegorías de un espíritu comunitario, una fuerza mayor, un ideal comparable, si no superior, al propuesto por el estado. Los reportajes estaban centrados en la ciudad, pero no en una de cambio urbanístico europeizado como lo era Lima, sino en una arquitectura sostenida por el pasado, en las ruinas antiguas y la historia de Cuzco, en sus calles y barrios. Como en otras páginas

\begin{tabular}{l}
1110 \\
\hline ISSN 0034-9631 (Impreso)
\end{tabular} 
de Variedades, el discurso presentaba una mezcla de diversos en negociación constante pues los reportajes incluían noticias de actualidad, como la visita del embajador de Estados Unidos, y crónicas acerca de la labor de los campesinos y las costumbres de los habitantes indígenas. El ideal ciudadano no se enfocaba en el habitante urbano que observa lo nuevo, sino en el del campo cuya vida cotidiana está siempre ligada al paisaje y a los orígenes de la comunidad.

López Lenci ha demostrado que, al principio del siglo veinte, la ciudad del Cuzco se volvió el eje de una serie de nuevas representaciones centradas en las nociones de origen y nación; representaciones que ambiciosamente buscaban transformar la historia cultural peruana. A este proceso se le conoce como Indigenismo. El Indigenismo fue un multifacético movimiento de reivindicación de la cultura andina, que elaboró una narrativa sobre el origen de la nación peruana centrada en el pasado prehispánico y en la ciudad de Cuzco. Dicho movimiento fue parte de un proceso de renovación cultural que empezó en la región cuzqueña con la Reforma de la Universidad San Antonio Abad iniciada en 1909. Los intelectuales que, junto con el rector norteamericano Albert A. Giesecke, lideraron la reforma (Luis E. Valcárcel, Felix Cossio y José Uriel García, entre otros) plantearon una modernización basada en el resurgimiento de las tradiciones andinas.

Los discursos del Indigenismo fueron, como afirma Jorge Coronado (1-2), una respuesta a los procesos de modernización del Perú y de la región cusqueña y elaboraron una propuesta sobre cómo esa región podía ser moderna. En un momento histórico en el cual Cuzco estaba experimentando cambios como el desarrollo urbano y la implementación de nuevos medios de transporte (telégrafo, teléfono, tranvía, carros), los intelectuales formaron una propuesta de identidad regional y nacional que se oponía al discurso centralista y estaba basado no en el mito de progreso linear sino en otro mito: el de una raza antigua, la indígena, y el de la ciudad del Cuzco como símbolo del pasado nacional (Mendoza 1-15). Siguiendo el modelo de Rowe, podemos entender el discurso indigenista como otra "declaración de modernidad", que se opone a, y compite con, aquella elaborada por políticos e intelectuales en Lima. La declaración indigenista no estaba basada en lo nuevo, la tecnología, la velocidad y el futuro, sino en una noción diferente de progreso que incluía las ruinas, el pasado prehispánico y la cultura indígena. Siguiendo esta hipótesis, Variedades se vuelve un objeto muy valioso puesto que es uno de los pocos artefactos culturales que contiene, y a la vez problematiza, ambas declaraciones de modernidad y que lo hace a nivel tanto textual como visual. La articulación de la propuesta indigenista en Variedades es claramente visible en la serie de reportajes gráficos.

Cuzco, como afirma López Lenci, fue "re-inventada" por intelectuales y fotógrafos a través de artículos, libros, ilustraciones, fotografías y guías, que construyeron una precisa cartografía de la ciudad, hecha tanto de su arquitectura (calles, edificios y ruinas) como habitantes, y que dieron forma a una idea de nación moderna alternativa

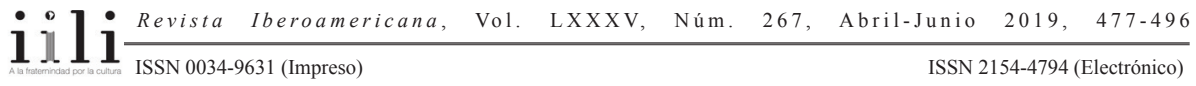


a aquella elaborada por el gobierno central en Lima. Los reportajes construyen Cuzco como "otra" con respecto a Lima: como el símbolo de la memoria prehispánica y del proceso histórico del mestizaje (López Lenci 345) que había dado forma a la nación peruana. En uno de los primeros reportajes, bajo el título de "Cuzco, la capital de los Inkas", Valcárcel (uno de los ideólogos principales del Indigenismo) presenta Cuzco como la cuna de la cultura inca y al mismo tiempo como una antigua ciudad en donde "los periodos y las civilizaciones coexisten" (Variedades n. 843). Las fotografías de la fortaleza de Sacsayhuaman de Chambi que acompañan el reportaje articulan visualmente los valores de la arquitectura inca, la "armonía, fuerza, simplicidad y simetría" que describen una fachada inca en otra imagen. En la ciudad de Cuzco, los habitantes del pasado son representados a través de ruinas, arquitectura (los muros incas) y calles; estos se vuelven los signos de las antiguas civilizaciones.

La "otredad" de Cuzco es construida en particular a través de sus calles. Uno de los reportajes está dedicado enteramente a ellas (Variedades n. 844) (fig.8), cuya construcción, según los indigenistas, remontaba al periodo inca: se les describe como "angostas, sombrías, [...] últimos vestigios de las reales mansiones de los Incas" que "evocan todos la historia prócer de este pueblo", como caminos secretos y misteriosos que conectan la antigua Cuzco con la ciudad actual y "escenarios de culminantes episodios [que], en las noches lunares [...], se pueblan de gentes arcaicas". Esta representación se opone a aquella de Lima, que en Variedades es presentada como una ciudad de grandes avenidas y espacios abiertos.

Variedades no solo mostró, sino que además "tradujo" la propuesta indigenista para su público a través de la noción de "lo pintoresco". Este término se emplea en muchos de los títulos de los reportajes etnográficos. ${ }^{6}$ Significativamente, lo pintoresco fue, como el costumbrismo, una tendencia

6 "Aspectos pintorescos de la vida del indio", "Costumbres pintorescas del Indio", "La sierra pintoresca”.

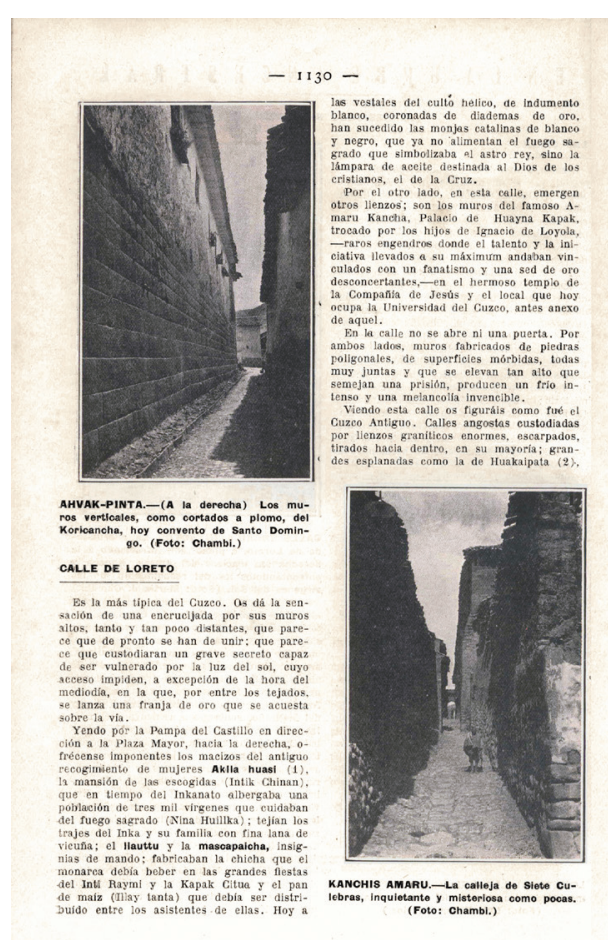

Fig. 8: Variedades n. 844, 1924

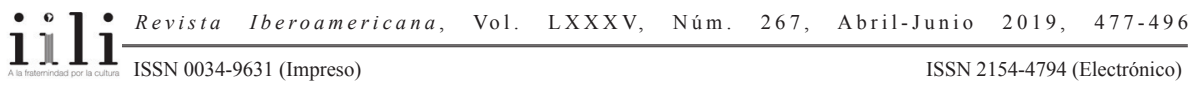


pictórica que se desarrolló en el contexto de la búsqueda iluminista por la autenticidad y tipicidad nacional (Ades 47, 53). En línea con una mirada costumbrista, y a través de lo pintoresco, la realidad andina fue presentada por Variedades como un atributo de la sociedad limeña, como su "otro" exótico. Lo pintoresco, en Variedades, se vuelve entonces una estrategia discursiva de mediación de la diferencia de una región definida "inédita" y ajena. Por su mirada "costumbrista" y "pintoresca", Variedades puede entenderse como la continuación de tradiciones visuales y maneras de ver desarrolladas en el contexto occidental y latinoamericano más de un siglo antes, y que se reformulan, a principios del siglo veinte, gracias a una nueva tecnología, la prensa ilustrada. Dicha revista formó parte activa de la constitución de las incipientes industria cultural y sociedad de masas así como del proceso de construcción nacional posindependencia.

En la historia cultural peruana, Variedades se presenta como otro de los "momento[s]" en los que la modernidad se hace "reconocible y legible" (Rowe 121). La modernidad que se declara, se expresa e inclusive se crea en una revista como Variedades, se articula como tecnología, temporalidad, espacialidad y ciudadanía. Es una modernidad de negociaciones (reales y simbólicas), tensiones y discursos que compiten entre ellos. En este proceso, Variedades se presenta como un espacio discursivo complejo, integrador e inclusivo que familiariza y suaviza, mas no resuelve, los antagonismos; que muestra otras facetas de lo que se ha llamado la heterogeneidad de la modernidad latinoamericana; ${ }^{7}$ y que, por su carácter serial, articula un "nacionalismo banal" (Billig 8) cambiante, fragmentario y precario.

\section{BibLIOGRAFíA}

Ades, Dawn. Art in Latin America. New Haven: Yale University Press, 1989.

Anderson, Benedict. Imagined Communities: Reflections on the Origin and Spread of Nationalism. 1983. London: Verso, 1991.

Bedoya, Ricardo. El cine silente en el Perú. Lima: Fondo Editorial de la Universidad de Lima, 2009.

Berman, Marshall. Todo lo sólido se desvanece en el aire. La experiencia de la modernidad. México DF: Siglo XXI, 2000.

Billig, Michael. Banal Nationalism. London: Sage Publications, 1995.

Bongers, Wolfgang. "Dossier: El cine entre 1900 y 1940: reflejos y reflexiones en la literatura chilena y otros discursos". Taller de Letras 46 (2010): 151-74.

Charney, Leo y Vanessa R. Schwartz. Cinema and the Invention of Modern Life. Berkeley: University of California Press, 1995.

Ver, por ejemplo, Quijano 1993.

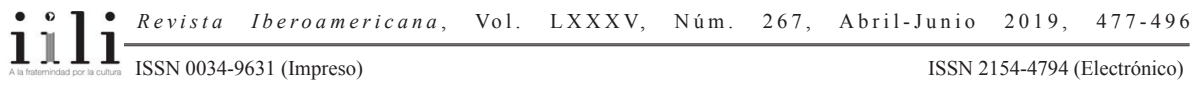


Contreras, Carlos y Marcos Cueto. Historia del Perú contemporáneo. Lima: Pontificia Universidad Católica del Perú, 2004.

Coronado, Jorge. The Andes Imagined. Indigenism, Society, and Modernity. Pittsburgh: University of Pittsburgh Press, 2009.

D’Argenio, Maria Chiara. "Modernidad, escritura 'nueva' y cine mudo en el Perú". Cine mudo latinoamericano: inicios, nación, vanguardias y transición. Aurelio De Los Reyes y David M.J. Wood, eds. México DF: UNAM, 2016. 191-208.

"A Picturesque Modernity in 1920s Peru and Argentina: Ruins, Cuzco and Americanism in the Photographic Reportages of Variedades and Plus Ultra." Journal of Latin American Cultural Studies 26/2 (2017): 221-51.

"From Spectators to Consumers: Citizenship in Latin American Illustrated Press (1880s-1930s)". Citizenship in the Latin American Upper and Middle Classes. Fiorella Montero Díaz y Franka Winter, eds. NY: Routledge, 2019. 11-29.

Espinoza, Juan Miguel. "Entre criollos y modernos: género, raza y modernidad criolla en el proyecto editorial de la revista Variedades (Lima, 1908-1919)". Historica XXXIX/1 (2015): 97-136.

López, Ana María. “'A Train of Shadows': Early Cinema and Modernity in Latin America". Through the Kaleidoscope. The Experience of Modernity in Latin America. Vivian Schelling, ed. London: Versus, 2000. 148-76.

López Lenci, Yasmín. El Cuzco, paqarina moderna. Cartografía de una modernidad e identidades en los Andes peruanos (1900-1935). Lima: UNMSM, 2004.

Mendoza, Zoila S. Creating our own. Folklore, Performance, and Identity in Cuzco, Peru. Durham: Duke University Press, 2008.

Miller, Nicola. Reinventing Modernity in Latin America. Intellectuals Imagine the Future, 1900-1930. Basingstoke: Palgrave Macmillan, 2008.

Mundial, 1921, n. 52 y 67.

Muñoz Cabrejo, Fanni. Diversiones públicas en Lima. 1890-1920. La experiencia de la modernidad. Lima: Red para el Desarrollo de las Ciencias Sociales en el Perú, 2001. Nuñez Gorriti, Violeta. El cine en Lima 1897-1929. Lima: Roxy Print Impresiones, 2010. Ossandón, Carlos B. y Eduardo Santa Cruz. El estallido de las formas. Chile en los albores de la 'cultura de masas'. Santiago de Chile: Lom Ediciones, 2005.

Quijano, Aníbal. "Modernity, Identity, and Utopia in Latin America". Boundary 2 20/3 (1993): 140-55.

Rogers, Geraldine. Caras y Caretas: Cultura, política y espectáculo en los inicios del siglo XX argentino. La Plata: EDULP. 2008. Memoria Académica. $<\mathrm{http} / / /$ memoria.fahce.unlp.edu.ar/libros/pm.413/pm.413.pdf>.

Rowe, William. "When Was Peru Modern? On Declarations of Modernity in Peru". En Nicola Miller y Stephen Hart, eds. When Was Latin America Modern? New York: Palgrave Macmillan, 2007. 121-145.

\begin{tabular}{l}
1110 \\
\hline ISSN 0034-9631 (Impreso)
\end{tabular} 
Vallejo, César. Artículos y Crónicas Completos I, II. Lima: PUCP, 2002.

Variedades. 1908-1932.

Wiesse, María. "Señales de nuestro tiempo". Amauta 4 (1926): 11-12.

Palabras clave: sensibilidad y vida modernas, Variedades, cine, ciudadanía imaginada Recibido: $\quad$ junio 2016

Aprobado: $\quad$ septiembre 2018 